\title{
Flumazenil in the Treatment of Dizziness and Vegetative Symptoms after Intravenous Infusion of Paclitaxel
}

\author{
Mariano Provencio Ruth Espinosa Antonio Sánchez Pilar España \\ Servicio de Oncología Médica, Hospital Universitario Puerta de Hierro, Madrid, Spain
}

Dear Editor,

On occasion, most frequently in middle-aged women, the intravenous infusion (IV) of paclitaxel produces symptoms of dizziness without the sensation of spinning objects that accompanies vegetative symptoms.

We describe the cases of 2 women diagnosed with ovarian carcinoma, FIGO stage III, who received chemotherapy based on a 21 day cycle of carboplatin, area under the curve (AUC) 5, plus paclitaxel $200 \mathrm{mg} / \mathrm{m}^{2}$ in $3 \mathrm{~h}$. A few minutes after commencing the infusion of paclitaxel, they experienced dizziness, vegetative symptoms, and general discomfort, however, the physical examination and vital signs were normal. In both patients, $0.5 \mathrm{mg}$ IV flunazenil was administered empirically, and they showed improvement within a few minutes, with complete recovery in the following $30 \mathrm{~min}$. During the second in fusion of paclitaxel, the patients presented the same symptoms. IV flunazenil was again administered, and they recovered immediately. In subsequent cycles, IV flunazenil was administered as a prophylaxis, and the symptoms did not reappear.
We believe that these symptoms are possibly related to the dehydrogenated ethanol in which the drug is dissolved. Ethanol acts on the central nervous system through multiple mechanisms some of which are not well known. Recent studies [1] have shown that one of these mechanisms is the modulation of the GABA-A receptor. The confluence of the action of ethanol and flunazenil with respect to the GABA-A receptor could explain the reversibility of the symptoms in our patients. Although further research is necessary in this respect, given that the administration of flumazenil is innocuous, we recommend that this drug may be used in women in whom these symptoms appear.

\section{Reference}

Chester JA, Cunningham CL: GABA(A) receptor modulation of the rewarding and aversive effects of ethanol. Alcohol 2002;26:131-143

\begin{tabular}{ll}
\hline KARGER & ๑ 2008 S. Karger GmbH, Freiburg \\
$\begin{array}{l}\text { Fax }+497614520714 \\
\begin{array}{l}\text { E-mail Information@Karger.de } \\
\text { www.karger.com }\end{array}\end{array}$ & Accessible online at: \\
www.karger.com/onk
\end{tabular}

